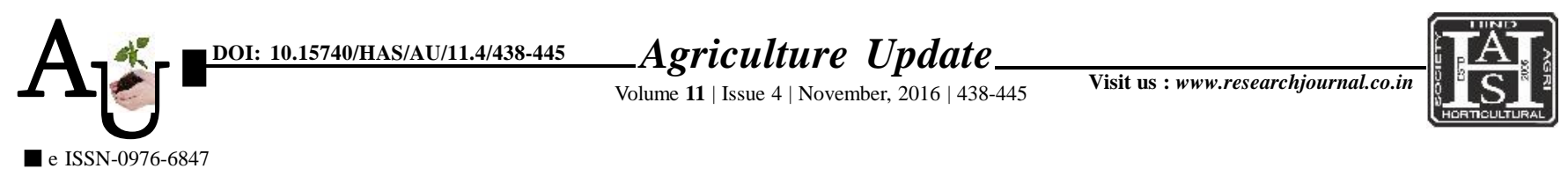

\title{
Research article: An assessment of awareness level of school going rural youth towards agriculture
}

GAYTRI TIWARI AND RUCHI GALUNDIA

Article Chronicle:

Received :

03.09.2016;

Revised :

06.10.2016;

Accepted :

22.10.2016

KEY WoRds :

Agriculture,

Awareness,

Socio-economic

status
SUMMARY : India is a developing nation and the youth constitutes almost more than half $(65 \%)$ of the population of the nation. The rapid growth and diversification of developmental activities have resulted in much needed expansion of employment opportunities, but at the same time have triggered rural to urban migration. This trend has inadvertently resulted in shift of farm labour to non-farm sectors. In the present scenario, creating awareness about agriculture among school going rural youth is a dire need. The present study was conducted to assess the socio-economic status of rural youth, to find out the awareness level of school going rural youth regarding agriculture and its various aspects and to analyze the corelation between socio-economic status of rural youth with their awareness about agriculture. The sample from three villages viz., Kavita, Chikalwas and Thoor consisted of 450 youth selected from three classes i.e. $7^{\text {th }}, 8^{\text {th }}$ and $9^{\text {th }}$. Standarized tool developed by Aggarwal (2005) was used to collect data for socio-economic status. Checklist was prepared to find out awareness about agriculture. Data was analysed by using corelation, frequency and mean and percentage distribution. Results revealed that there was significant relationship between socio-economic status and agriculture awareness of rural youth. Majority of the respondents were from low and medium socio-economic status and had average awareness about agriculture and its various aspects. Proper steps should be taken at G.Os and N.G.Os level for channelizing youth towards agriculture for its sustainability.

How to cite this article : Tiwari, Gaytri and Galundia, Ruchi (2016). An assessment of awareness level of school going rural youth towards agriculture. Agric. Update, 11(4): 438-445; DOI : 10.15740/HAS/AU/11.4/438-445.

\section{GAYTRI TIWARI}

Department of Human

Development and

Family Studies, College

of Home Science,

Maharana Pratap

University of Agriculture

and Technology,

UDAIPUR (RAJASTHAN)

INDIA

See end of the article for

authors' affiliations 